\title{
Accessibility from Scratch: One Library's Journey to Prioritize the Accessibility of Electronic Information Resources
}

\section{Author: Kirsten Ostergaard}

This is a postprint of an article that originally appeared in The Serials Librarian on Sept 11, 2015.". http://dx.doi.org/10.1080/0361526X.2015.1069777

Kirsten Ostergaard (2015): Accessibility from Scratch: One Library's Journey to Prioritize the Accessibility of Electronic Information Resources, The Serials Librarian,69:1-14, 2015 DOI: 10.1080/0361526X.2015.1069777 


\title{
Accessibility from Scratch: One Library's Journey to Prioritize the Accessibility of Electronic Information Resources
}

\author{
KIRSTEN OSTERGAARD \\ Montana State University, Bozeman, Montana, USA
}

The increased development and use of electronic and information technology in higher education raises questions about accessibility for individuals with disabilities. In academic libraries, providing accessible electronic information resources ensures equal access and opportunity to information. This article provides a contextual understanding of accessibility in higher education as well as strategies for evaluating, negotiating, and procuring accessible electronic resources licensed through third party vendors.

KEYWORDS accessibility, academic libraries, electronic information resources, electronic and information technology (EIT), voluntary product accessibility template (VPAT), Web content accessibility guidelines (WCAG), Section 508

\section{INTRODUCTION}

The Montana State University (MSU) Library is implementing an accessibility plan to acquire accessible electronic information resources. The growing use of electronic and information technology (EIT) in the classroom is changing the landscape of education, connecting students to a wealth of information, and creating dynamic new learning experiences. In many cases, however, EIT has created barriers to education for students with disabilities. As a result, equal access and opportunity in education has been compromised.

(C) Kirsten Ostergaard

Address correspondence to Kirsten Ostergaard, Electronic Resources \& Discovery Services Librarian, Montana State University, P.O. Box 173320, Bozeman, MT 59717-3320, USA. E-mail: kirsten.ostergaard@montana.edu 
Library users have diverse needs. Regardless of visual, physical, developmental, or learning abilities, it is our role to ensure these needs are met. Accessible EIT is designed for use by people with the widest range of abilities and disabilities. ${ }^{1}$ The first principle in the American Library Association (ALA) Code of Ethics expresses a commitment to providing the highest level of service to all library users. ${ }^{2}$ By establishing an understanding of what accessible EIT means and a commitment to improved access, academic libraries can develop and incorporate a plan into their workflow that supports the inclusivity of our diverse user communities.

This article will establish concepts of accessible EIT and review recent cases involving inaccessible EIT in higher education. From there the article turns to federal legislation for an understanding of how individuals with disabilities are protected from discrimination in the United States. Lastly, the article will explore strategies to implement an accessibility plan in your acquisitions process. The University of Montana (UM) recently reached a resolution agreement with the U.S. Department of Education, Office for Civil Rights to make all EIT on campus fully accessible. This legal case is particularly notable because it is the first involving a branch of the federal government that cites inaccessible library resources. Members of the Montana State University (MSU) Library, "sister institution to the University of Montana," have gleaned from the experiences at UM in the creation and implementation of their accessibility plan. It should be noted that this article will not provide an examination of accessibility and usability testing. While the value of usability testing cannot be underscored, this article will focus on providing a contextual framework for incorporating accessibility in the procurement process.

\section{ACCESSIBLE EIT}

The use of technology and the Internet are increasingly essential components of education, the modern workplace, and everyday life. The web serves as an access point to a wealth of information and interaction. EIT presents many opportunities for education, innovation, commerce, and community. When EIT is developed with accessibility in mind, all users have equal access and opportunity to interact with, contribute to, and understand information. Accessible EIT removes barriers and enables people with disabilities to more actively participate in society. ${ }^{3}$

EIT, including Internet websites, databases, learning management systems, or classroom technologies, is made accessible when it needs no assistive technologies or is compatible with assistive technologies. ${ }^{4}$ Inaccessible EIT presents barriers to information and interaction for the disabled and can range from websites with poorly labeled page elements, to unreadable Portable Document Format (PDF) files, or streaming media services without 
closed captioning for viewers. Inaccessible EIT not only negatively affects students with disabilities, but may require additional modifications to comply with accessibility standards. For example, a streaming audio service that does not provide transcripts for the hearing impaired may warrant additional labor to produce transcripts. These one-shot modifications, however, can be time consuming, cost prohibitive, and redundant.

Katie Ellis and Gerard Michael Goggin encourage us in Reimagining the Good Life with Disability, to think about new ways of creating that embrace disability rather than reject it as something that needs to be overcome or cured. $^{5}$ In higher education, this means establishing an institutional commitment to creating a more holistic learning environment for all students; one in which disability does not impede the learning experience, but is rather incorporated into the environment. ${ }^{6}$ History has shown that when products and services are designed for the disabled, there are unintended, yet serendipitous, benefits for other segments of the population. For example, closed captioning on televisions is used widely at gyms and in restaurants. Curb cuts, the ramps found transitioning from sidewalks to roadways, originally intended to accommodate individuals in wheelchairs, are used heavily by people pushing strollers or riding bikes, and servicemen and women transporting goods into stores. Improving access to products and services not only serves individuals with disabilities, but enriches society by encouraging understanding, perspective, and increased involvement through inclusive practices. Accessible EIT is the next step in that legacy.

\section{KEY CASES}

In higher education, colleges and universities are required to comply with disabilities rights laws that protect students with disabilities from discrimination. However, accessibility for EIT is complex and wide-ranging. Some key cases involving library resources, include:

- 2013, University of California, Berkeley. In 2013 the University of California, Berkeley entered into a Settlement Agreement with the Disability Rights Advocates to improve access to school materials for students with print disabilities. ${ }^{7}$ A print disabled person "cannot effectively read print because of a visual, physical, perceptual, developmental, cognitive, or learning disability." 8 The Disability Rights Advocates, an organization dedicated to protecting the civil rights of people with disabilities, ${ }^{9}$ represented three students at UC Berkeley and successfully negotiated a solution with UC Berkeley. New policies and procedures now ensure the resources are in place to provide access to written material for the print disabled. 
- 2013, Penn State University. In 2013 Penn State University agreed to a voluntary Resolution Agreement with the National Federation for the Blind "as part of the U.S. Department of Education, Office for Civil Rights (OCR) Early Complaint Resolution (ECR) process" ${ }^{10}$ to resolve access issues to computer and web-based technologies that were inaccessible to blind students and faculty. The National Federation for the Blind is committed to equal rights for the blind by removing legal, economic, and social discriminations. ${ }^{11}$ As a result of this resolution agreement, Penn State University committed to making all EIT accessible to blind students, faculty, and staff.

- 2014, University of Montana. In 2014 UM reached a Resolution Agreement with the U.S. Department of Education, OCR to resolve the inaccessibility of electronic and information technology across campus. ${ }^{12}$ Similar to Penn State, UM committed to implementing a plan that makes all EIT fully accessible. As a part of their resolution agreement, UM must provide the OCR with reports documenting progress of accessibility measures.

In all of these cases library resources are explicitly referenced. The inaccessible library resources cited in complaints include websites, databases, and an online catalog system. Of these three cases, the University of California, Berkeley and Penn State University reached settlement agreements with nonprofit organizations. The University of Montana is the only case in which library resources are referenced, to reach a resolution agreement with a branch of the federal government. With that in mind, let's explore how accessibility is defined in the UM Resolution Agreement as well as review legislation in place to protect the disabled from discrimination in higher education.

\section{LAW}

According to the UM Resolution Agreement, when something is accessible, it means that "individuals with disabilities are able to independently acquire the same information, engage in the same interactions, and enjoy the same services within the same timeframe as individuals without disabilities, with substantially equivalent ease of use."13 Accessible EIT does not require delayed accommodation. Angela Dresselhaus defines an accessible library resource as "the ability [of persons with visual, perceptual or physical disabilities] to obtain the same information, at the same time, for the same price and at the same quality [as persons with no disability]." ${ }^{4}$ Accessible EIT empowers disabled students, faculty, and staff to participate in the educational process in real time, without undue burden. In 2010, the U.S. Department of Justice, Civil Rights Division (DOJ CRD), and the U.S. Department of Education, Office for Civil Rights (ED OCR) together wrote 
a "Dear Colleague" letter stating that the required use of technology that is inaccessible to an entire population of individuals with disabilities is discrimination prohibited by the Americans with Disabilities Act of 1990 (ADA) and Section 504 of the Rehabilitation Act of $1973 .{ }^{15}$ The Departments request that all colleges and universities work to ensure that technology used in education is accessible to all individuals, regardless of ability.

Both the departments of Education and Justice share responsibility for enforcing the ADA and Section 504 of the Rehabilitation Act. Table 1 details the legislation in place to protect the rights of individuals with disabilities in higher education.

In the last five years, many lawsuits between academic institutions and the federal government have centered on the accessibility of EIT. Electronic and information technology is defined as "information technology and any interconnected system or subsystem of equipment that is used in the creation, conversion, or duplication of data or information." 23 EIT can include Internet websites, databases, learning management systems, and classroom technologies, among other things. Currently, standards defined in Section 508 of the Rehabilitation Act require federal agencies to make their EIT accessible to people with disabilities. ${ }^{24}$ By requiring federal agencies to develop, procure, and maintain EIT that is accessible, Section 508 calls for proactively accessible EIT. This reframes expectations about how services and products are available to the disabled. The standards set forth in Section 508 of the Rehabilitation presently only apply to federal agencies. However, the Department of Education is increasingly referencing Section 508 for guidance or as a requirement for accessible EIT in lawsuits with academic institutions, including the University of Montana (http:// www.umt.edu/accessibility/docs/FinalResolutionAgreement.pdf), University of Cincinnati (http://www.nacua.org/documents/UniversityCincinnatiDOE WebsiteAagreement.pdf), and Youngstown State University (http://www. nacua.org/documents/YoungstownStateUniversityAgreement.pdf), to name a few.

Ready-made, accessible EIT is still a work in progress. However, the federal government and academic institutions can cooperate and move the market to improve access by creating accessible content and contracting with vendors that provide accessible EIT products and services.

\section{ASSESSMENT TOOLS}

When acquiring new electronic information resources, it is important to understand what is required for a product or service to be accessible and to document procurement decisions relative to accessibility compliance. There are two tools in place to guide accessible acquisitions, the Voluntary Product Accessibility Template (VPAT) and the Web Content Accessibility Guidelines 


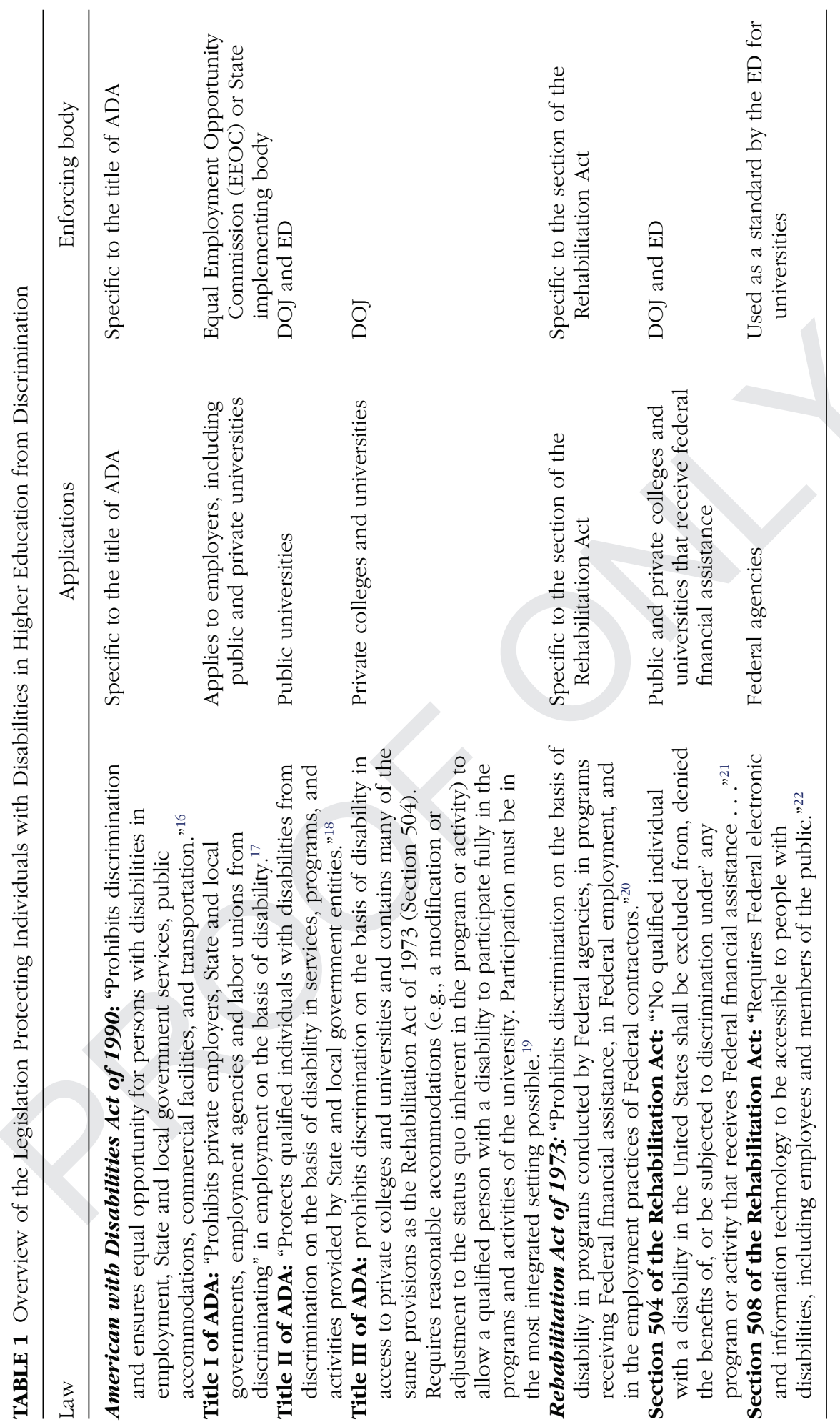


(WCAG). The purpose of the VPAT is to assist Federal agencies and other buyers assessing commercial EIT products and services for features that support accessibility. ${ }^{25}$ These could include, for example, software and hardware products. The Web Content Accessibility Guidelines are industry best practices used to evaluate accessible web content. ${ }^{26}$ Let's take a closer look at each of these tools and how they can be used in the procurement process.

Voluntary Product Accessibility Template (VPAT): The VPAT was developed for federal contracting officials to acquire accessible EIT. It is a tool created for vendors to assist with this process. A VPAT is a document that details requirements for compliance with Section 508 of the Rehabilitation Act. Vendors respond to relevant sections of the document disclosing how their software or IT products support each criteria. ${ }^{27}$ Once completed, federal agencies and buyers can then review VPAT forms to evaluate the accessibility of a product and identify any potential deficiencies. There are eight criteria in a VPAT form that reference elements of Section 508 of the Rehabilitation Act, including:

1. Section 1194.21 Software Applications and Operating Systems

2. Section 1194.22 Web-based Internet Information and Applications

3. Section 1194.23 Telecommunications Products

4. Section 1194.24 Video and Multi-media Products

5. Section 1194.25 Self-Contained, Closed Products

6. Section 1194.26 Desktop and Portable Computers

7. Section 1194.31 Functional Performance Criteria

8. Section 1194.41 Information, Documentation and Support

Official VPAT forms can be accessed on the U.S. Department of State website: http://www.state.gov/m/irm/impact/126343.htm.

Web Content Accessibility Guidelines (WCAG): The World Wide Web Consortium (W3C) established standards for accessible web content called the Web Content Accessibility Guidelines (WCAG). The federal government uses WCAG as a metric for evaluating web content. ${ }^{28}$ Web content constitutes information in a web page or a web application, including text, images, and sounds. ${ }^{29}$ WCAG 2.0 is a technical standard that can be applied to academic institutions. It consists of 12 guidelines organized into four principles: perceivable, operable, understandable, and robust. The W3C has organized each guideline so that it can be measured by success criteria at one of three levels: A, AA, or AAA. ${ }^{30}$ The University of Montana Resolution Agreement requires bidders to meet the accessibility standards of WCAG 2.0 Level AA for web-based technology. ${ }^{31}$

Libraries can take advantage of these tools when negotiating with vendors 225 during the acquisitions process. A VPAT would be requested in instances where a library is procuring an EIT product or service. Information about 
WCAG 2.0 compliance would be requested when negotiating with vendors or publishers that maintain a web interface. In many cases, requesting a VPAT as well as a WCAG statement may be appropriate.

With an understanding of accessible EIT, the laws in place to protect the rights of the disabled, and tools to evaluate EIT, let's turn now to strategies you can employ at your library. The Montana State University Library is implementing a plan that prioritizes the accessibility of electronic information resources. The following steps describe strategies and considerations to incorporate into your procurement processes.

\section{Strategies for Acquiring Accessible Electronic Information Resources}

\section{STEP 1: CONNECT with INSTITUTIONAL ADMINISTRATION AND Disability SERVICES}

One of the first steps to begin analyzing the library's role in accessible electronic resource acquisitions is to connect with university administration and disability services to learn about accessibility on campus.

- Research federal and state laws that protect the disabled and apply to your academic institution. Determine what level of accessibility is required for EIT products and services.

- Inquire about campus policies and resources in place for faculty and staff in support of accessibility compliance.

- Establish an understanding of the role of disability services. What does the disabled population on your campus look like? What services and assistive technologies are available?

Connecting with departments across campus presents numerous opportunities for increased awareness, understanding, participation, and partnership that benefit and further the mission of accessibility. The library can learn about challenges that disability services faces and perhaps identify opportunities for improved products and services. Furthermore, libraries gain insight into requirements for accessibility, which in turn, instructs communication with third party vendors.

\section{Step 2: Modify Collection Development Policy}

The second step is to modify your Collection Development policy to include language valuing accessible electronic resources. The following example is in effect at the MSU Library:

CD Policy: The Montana State University Library is committed to providing accessible electronic information resources to individuals with 
disabilities. We make every effort to gather information and prioritize the acquisitions of accessible electronic information resources, except in cases where a product or service would be fundamentally altered.

The MSU Library is still actively learning about accessibility and all the ways in which the library can improve services. By modifying our Collection Development policy, we express a commitment to improving access to electronic products and services.

\section{STEP 3: COMmunicate WiTH Vendors}

Electronic information resources can include eJournals, eBooks, database collections, streaming media services, and other interactive web services. It is important to ensure that the content and the platforms of electronic information resources are accessible. Communicate with vendors about your institution's accessibility needs. When negotiating with vendors:

- Inquire about the accessibility of electronic products.

- Require that vendors adhere to legal requirements (federal, state, and provincial laws) for accessibility. Accordingly, request VPATs in support of this mission and to inform electronic resources acquisitions.

- Request that vendors meet WCAG 2.0 best practices for accessible web content.

- Inquire about content file formats (e.g., Portable Document Format [PDF], TXT, or Hyper Text Markup Language [HTML]). Is the content directly accessible or is it compatible with assistive technologies? If not, does the vendor plan to meet accessibility requirements in the future?

- Require vendors to incorporate a clause in license agreements that clearly defines the accessibility of their products. The 2012 Report of the ARL Joint Task Force on Services to Patrons with Print Disabilities includes model licensing language for consideration. ${ }^{32}$

- In the event that a vendor's product is inaccessible, explore negotiations allowing for the content to be adapted into accessible formats at your academic institution or by a third party. ${ }^{33}$

Gathering information empowers your library to make informed procurement decisions. Furthermore, communicating with vendors and explaining your institution's accessibility requirements leads to improved product development. As vendors learn what is important to libraries, they can begin to think strategically about where and how to improve their products. $^{34}$

The following template was designed and adapted from the University of Montana's Mansfield Library. It is employed by MSU Library and serves as 
a starting place to begin thinking about how you communicate with vendors about current subscriptions. As you draft up language, define your institution's requirements. You may consider contacting your institution's legal counsel or procurement office if further review is necessary.

TO THE WEB ACCESSIBILITY COORDINATOR:

The Library has modified its Collection Development policy to prioritize the accessibility of electronic and information technology resources. In accordance with Section 504 of the Rehabilitation Act and Title II of the Americans with Disabilities Act, our goal is to provide equal access and opportunity to our patrons. Accordingly, we request that each electronic resource provider adhere to Level AA of the Web Content Accessibility Guidelines (WCAG) 2.0 published by the W3C's Web Accessibility Initiative.

We ask that you submit documentation about WCAG conformance as well as a Voluntary Product Accessibility Template (VPAT). The VPAT Documentation can be found on the U.S. Department of State website: http://www.state.gov/ $\mathrm{m} / \mathrm{irm} / \mathrm{impact} / 126343 . \mathrm{htm}$. Please send a completed VPAT to by

\section{Step 4: Document Feedback And Assess Product Accessibility}

Carefully document communication with vendors and any procurement decisions. Gather forms for review and work in collaboration with your procurement or disabilities services offices to identify someone to assist with reviewing VPATs. Pledging to evaluate and procure accessible electronic information resources and allocating the personnel and financial resources to do so is critical for the success of improved access.

Acquisitions budgets have historically been defined as monies designated for procuring new resources. Academic libraries acquire new resources to provide access to information. These resource types include print resources, electronic resources, maps, movies, and music, to name a few. As libraries increasingly encourage open access publishing models and acquire electronic information resources to optimize discovery, remote, and mobile access, improved accessibility can be integrated into this budgeting model. The MSU Library has renamed the Acquisitions Budget to Access Budget. Allocating funds to review, acquire, and in some cases convert electronic resources to an accessible format falls under the purview of this new budgeting model and supports access to information. 


\section{STeP 5: Designate a Library Liaison to Disability SERVices}

Designate a liaison to partner with disability services. Liaisons maintain open lines of communication between departments that may not otherwise interact. A liaison to disability services can keep abreast of developments and trends in assistive technologies and participate in the campus accessibility dialogue. By understanding the changing needs and practices of our students and disability services, library liaisons are poised to support student success, improve access to information, and advance the library's mission within the larger institution. ${ }^{35}$

The next, more advanced step to ensuring accessibility is usability testing. Accessibility does not necessarily equate to or guarantee the usability of a service or product. Usability is a system's ability to perform the specific task for which it was designed when utilized by individuals with the widest range of capabilities. ${ }^{36}$ For students interacting regularly with electronic information resources, usability is essential for student success. Conduct usability tests with disabled students, faculty, and staff for more comprehensive product evaluations. In fact, accessibility scans of electronic resources often reveal performance problems and discrepancies with information in a vendor VPAT. Libraries can help overcome barriers to information by working with disability services and vendors to document and address the usability barriers users encounter. ${ }^{37}$ Usability tests expose flaws in vendor products and increase an understanding of the difficulties that students with disabilities face when interacting with EIT.

\section{CONCLUDING THOUGHTS}

The rapid development and use of EIT in everyday life presents new opportunities for interaction, education, commerce, and community. EIT is connecting people and information in radically new ways. Accessible EIT is critical to ensuring equal access and opportunity to information, services, and products for all segments of the population, including the disabled. In higher education, academic libraries can support and improve access to electronic information resources by embedding accessibility measures in the acquisitions process. In addition to integrating accessibility locally, professional collaboration is essential to reduce redundancies and work more efficiently. Laura DeLancey created a VPAT Repository (http://uniaccessig. org/lua/vpat-repository/) to house vendor VPATs, accessibility statements, and finding aides. Libraries can contribute by requesting vendors to submit VPATs and any other supporting documentation to the repository during the negotiation process. Likewise, it is important for usability test results to be shared broadly and widely. Inaccessible electronic information resources are unacceptable. As vendors continue to develop and update their products 
and services, it is critical that libraries stay abreast of changing legislation and accessibility standards to effectively negotiate and demand accessible electronic information resources. Together, the work of libraries and profressional organizations, like the Association of College and Research Libraries (ACRL)'s Universal Accessibility Interest Group (http://www.ala. org/acrl/aboutacrl/directoryofleadership/interestgroups/acr-igua) and LITA's Accessibility Interest Group (http://www.ala.org/lita/about/igs/universal/litiguacc) can support the needs of our user communities and improve access to information. Together we can advocate for the development and rigorous testing of proactively accessible electronic information resources.

\section{REFERENCES}

1. "What Is Accessible Electronic and Information Technology?" AccessibleTech.org. Accessed May 21, 2015. http://accessibletech.org/access_ articles/general/whatIsAccessibleEIT.php.

2. "Code of Ethics of the American Library Association." American Library Association. Accessed April 11, 2015. http://www.ala.org/advocacy/proethics/ codeofethics/codeethics.

3. "Introduction to Web Accessibility." W3C Web Accessibility Initiative. Accessed April 12, 2015. https://www.w3.org/WAI/intro/accessibility.php.

4. "What Is Accessible Electronic and Information Technology?" AccessibleTech. org. Accessed May 25, 2015. http://accessibletech.org/access_articles/general/ whatIsAccessibleEIT.php.

5. Meryl Alper, Elizabeth Ellcessor, Katie Ellis, and Gerard Goggin, "Reimagining the Goood Life with Disability: Communication, New Technology, and Humane Connections."(2015).

6. Tatiana I. Solovieva and Jeremy M. Bock, "Monitoring for Accessibility and University Websites: Meeting the Needs of People with Disabilities." AHEADAssociation 27, no. 2 (2014): 113-127.

7. "Landmark Agreement Big Step Forward for Students with Print Disabilities." Disability Rights Advocates. May 7, 2013. Accessed April 24, 2015. http://www. dralegal.org/pressroom/press-releases/landmark-agreement-big-step-forwardfor-students-with-print-disabilities.

8. "The Definition of 'Print Disabled'?" Reading Rights Coalition. Accessed May 16, 2015. http://www.readingrights.org/definition-print-disabled.

9. "About Disability Rights Advocates." Disability Rights Advocates. Accessed April 24, 2015. http://www.dralegal.org/about.

10. "Settlement Between Penn State University and National Federation of the Blind." Pennsylvania State University. Accessed April 12, 2015. http:// accessibility.psu.edu/nfbpsusettlement/.

11. "What Is the National Federation of the Blind?" National Federation of the Blind. Accessed April 24, 2015. https://nfb.org/who-we-are.

12. "Resolution Agreement." U.S. Department of Education, Office for Civil Rights. 2014. Accessed April 11, 2015. http://www.umt.edu/accessibility/docs/Final ResolutionAgreement.pdf 
13. "Resolution Agreement." U.S. Department of Education, Office for Civil Rights. 2014. Accessed April 11, 2015. http://www.umt.edu/accessibility/docs/Final ResolutionAgreement.pdf.

14. Angela Dresselhaus, "The Americans with Disabilities Act Compliance and Library Acquisitions," Acquisitions Institute at Timberline Lodge. May 2013. Accessed May 25, 2015. http://works.bepress.com/angela_dresselhaus/24.

15. Thomas Perez and Russlynn Ali, "Joint-Dear Colleague Letter: Electronic Book Readers." U.S. Department of Education. June 29, 2010. Accessed May 25, 2015. http://www2.ed.gov/about/offices/list/ocr/letters/colleague-20100629.html.

16. "The Americans with Disabilities Act of 1990 and Revised ADA Regulations Implementing Title II and Title III." ADA.gov. Accessed May 27, 2015. http:// www.ada.gov/2010_regs.htm.

17. "Employment (Title I)." ADA.gov. Accessed May 27, 2015. http://www.ada.gov/ ada_title_I.htm.

18. "State and Local Governments (Title II)." ADA.gov. Accessed May 27, 2015. http://www.ada.gov/ada_title_II.htm.

19. "Public Accommodations and Commercial Facilities (Title III)." ADA.gov. Accessed May 27, 2015. http://www.ada.gov/ada_title_III.htm.

20. "A Guide to Disability Rights Laws." ADA.gov. April 9, 2012. Accessed May 27, 2015. http://www.ada.gov/cguide.htm.

21. "A Guide to Disability Rights Laws." ADA.gov. April 9, 2012. Accessed May 27, 2015. http://www.ada.gov/cguide.htm.

22. "Section 508 Of The Rehabilitation Act." Section508.gov. Accessed May 27, 2015. http://www.section508.gov/Section-508-Of-The-Rehabilitation-Act.

23. "Resolution Agreement." U.S. Department of Education, Office for Civil Rights. 2014. Accessed April 11, 2015. http://www.umt.edu/accessibility/docs/Final ResolutionAgreement.pdf.

24. "Section 508 Of The Rehabilitation Act." Section508.gov. Accessed April 14, 450 2015. http://www.section508.gov/Section-508-Of-The-Rehabilitation-Act.

25. "Voluntary Product Accessibility Template (VPAT)." NC State University IT Accessibility. Accessed April 30, 2015. http://accessibility.oit.ncsu.edu/training/ accessibility-handbook/vpat.html.

26. "Web Content Accessibility Guidelines (WCAG) Overview." W3C Web Accessibility Initiative. Accessed May 10, 2015. http://www.w3.org/WAI/intro/ wcag.

27. "Voluntary Product Accessibility Template (VPAT) Policy \& Information." U.S. Department of State. Accessed May 25, 2015. http://www.state.gov/m/irm/ impact/126340.htm.

28. "Summary of Section508 Standards." Section508.gov. Accessed May 9, 2015. http://www.section508.gov/summary-section508-standards.

29. "Web Content Accessibility Guidelines (WCAG) Overview." W3C Web Accessibility Initiative. Accessed May 9, 2015. http://www.w3.org/WAI/intro/ wcag.

30. "Web Content Accessibility Guidelines (WCAG) Overview." W3C Web Accessibility Initiative. Accessed May 9, 2015. http://www.w3.org/WAI/intro/ wcag. 
31. "Resolution Agreement." U.S. Department of Education, Office for Civil Rights. 2014. Accessed May 13, 2015. http://www.umt.edu/accessibility/docs/Final ResolutionAgreement.pdf.

32. "Report of the ARL Joint Task Force on Services to Patrons with Print Disabilities." Association of Research Libraries. November 2, 2012. Accessed May 10, 2015. http://www.arl.org/storage/documents/publications/print-disabilitiestfreport02nov12.pdf.

3. "Report of the ARL Joint Task Force on Services to Patrons with Print Disabilities." Association of Research Libraries. November 2, 2012. Accessed May 10, 2015. http://www.arl.org/storage/documents/publications/ print-disabilities-tfreport02nov12.pdf.

34. "Accessibility Information Toolkit for Libraries." Ontario Council of University Libraries. 2013. Accessed May 25, 2015. http://ocul.on.ca/sites/default/files/ OCULAccessibilityToolkit-ENG-v2.0 (May2014).pdf.

35. Janice Jaguszewski and Karen Williams, "New Roles for New Times: Transforming Liaison Roles in Research Libraries." August, 2013. Accessed May 23, 2015, http://conservancy. umn. edu/bitstream/handle/11299/169867/ TransformingLiaisonRoles. pdf? sequence $=1 \&$ isAllowed $=y$.

36. Federici, Stefano, Andrea Micangeli, Irene Ruspantini, Stefano Borgianni, Fabrizio Corradi, Emanuele Pasqualotto, and Marta Olivetti Belardinelli, "Checking an Integrated Model of Web Accessibility and Usability Evaluation for Disabled People." Disability E Rehabilitation 27, no. 13 (2005): 781-790.

37. Laura DeLancey, "Assessing the Accuracy of Vendor-Supplied Accessibility Documentation." Library Hi Tech 33, no. 1 (2015): 103-113. 